\title{
Optimal signal detection with neuronal diversity: balancing the gullible and the prudent neurons
}

\author{
Leonardo L Gollo ${ }^{1 *}$, Mauro Copelli², James A Roberts ${ }^{1}$ \\ From 24th Annual Computational Neuroscience Meeting: CNS*2015 \\ Prague, Czech Republic. 18-23 July 2015
}

Network connectivity have been shown to play an important role in shaping the neuronal dynamics [1-5]. A complementary remarkable feature of neuronal systems is the large degree of morphological and functional diversity. Despite some recent efforts in understanding the role of neuronal diversity embedded in a network [6-9], the benefits of cellular variability to distinguish input varying over orders of magnitude remain elusive.

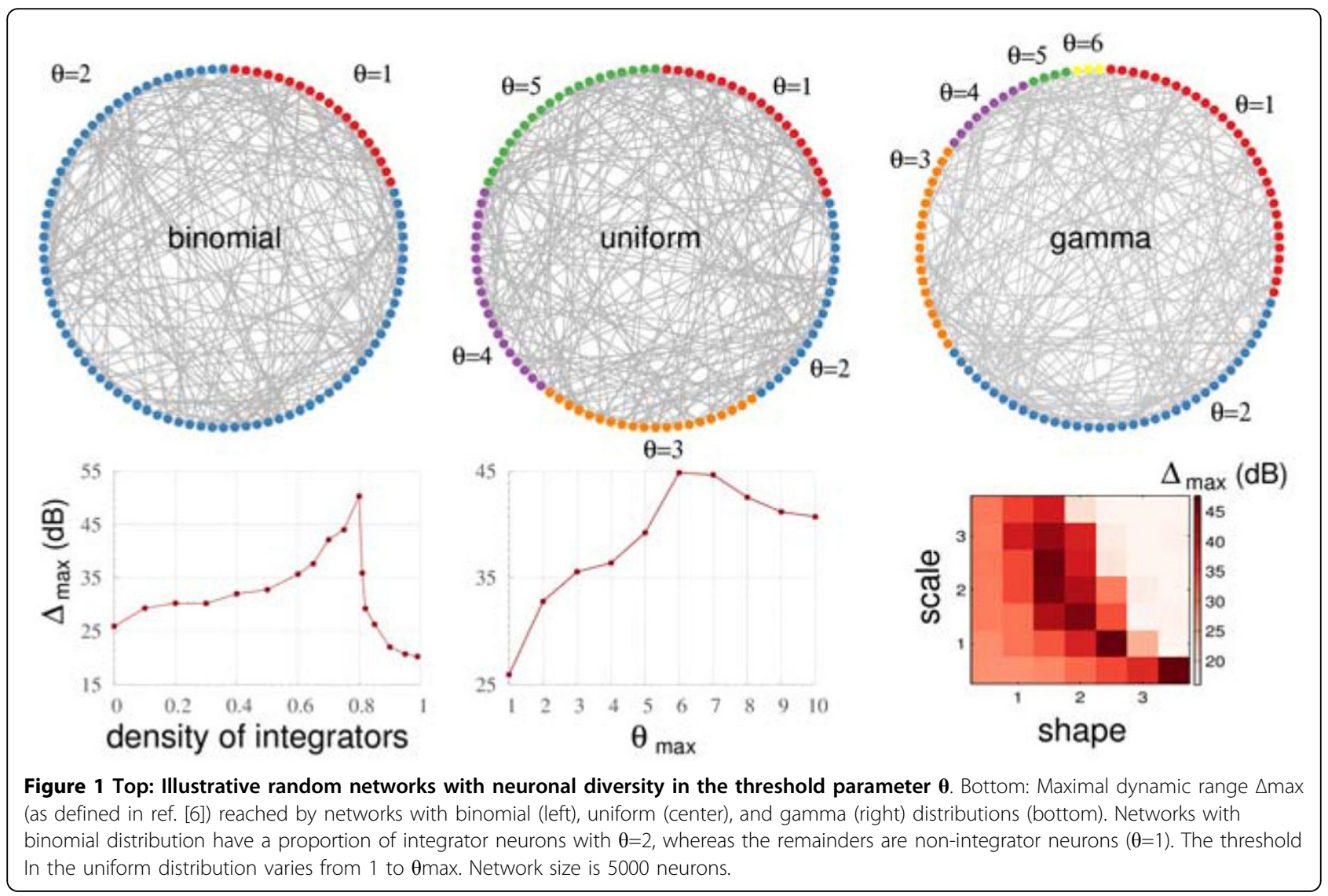

\footnotetext{
* Correspondence: leonardo.l.gollo@gmail.com

'Systems Neuroscience Group, QIMR Berghofer, Brisbane, Queensland,

Australia

Full list of author information is available at the end of the article
}

(c) 2015 Gollo et al. This is an Open Access article distributed under the terms of the Creative Commons Attribution License (http:// 
We utilize a simple quiescent-active-refractory-quiescent model, which is amenable to mathematical analysis [10], interacting in a (non-structured) random network with diversity in the parameter that controls the propensity of the neurons to fire in response to input from their neighbors. We consider a simple binomial distribution, a uniform distribution, and a more realistic gamma distribution. As depicted in Figure 1, we show that the capability of the network to distinguish the amount of external input can be improved by two orders of magnitude $(20 \mathrm{~dB})$ in the presence of diversity. We explain how diversity enhances the network capabilities, and identify the cases in which one specialized sub-population outperforms the rest of the network and the cases in which the average network outperforms any subpopulation. Finally, we show the robustness of our results in a balanced cortical network of excitatory and inhibitory neurons.

\section{Authors' details}

'Systems Neuroscience Group, QIMR Berghofer, Brisbane, Queensland, Australia. ${ }^{2}$ Departmento de Física, Universidade Federal de Pernambuco, Recife, Pernambuco, Brazil.

Published: 18 December 2015

\section{References}

1. Gollo LL, Zalesky A, Hutchison RM, van den Heuvel M, Breakspear M: Dwelling quietly in the rich club: brain network determinants of slow cortical fluctuations. Phil Trans R Soc B 2015, 370(1668).

2. Matias FS, Gollo LL, Carelli PV, Bressler SL, Copelli M, Mirasso CR: Modeling positive Granger causality and negative phase lag between cortical areas. Neurolmage 2014, 99:411-418.

3. Gollo LL, Mirasso C, Sporns O, Breakspear M: Mechanisms of zero-lag synchronization in cortical motifs. PLoS Comput Biol 2014, 10(4):e1003548.

4. Gollo LL, Breakspear M: The frustrated brain: from dynamics on motifs to communities and networks. Phil Trans R Soc B 2014, 369(1653):20130532.

5. Moretti P, Muñoz MA: Griffiths phases and the stretching of criticality in brain networks. Nat Commun 2013, 4.

6. Gollo LL, Mirasso C, Eguíluz VM: Signal integration enhances the dynamic range in neuronal systems. Phys Rev E 2012, 85(4):040902.

7. Mejias JF, Longtin A: Optimal heterogeneity for coding in spiking neural networks. Phys Rev Lett 2012, 108(22):228102.

8. Vladimirski BB, Tabak J, O'Donovan MJ, Rinzel J: Episodic activity in a heterogeneous excitatory network, from spiking neurons to mean field. J Comput Neurosci 2008, 25(1):39-63.

9. Tessone CJ, Mirasso CR, Toral R, Gunton JD: Diversity-induced resonance. Phys Rev Lett 2006, 97(19):194101.

10. Gollo LL, Kinouchi O, Copelli M: Statistical physics approach to dendritic computation: The excitable-wave mean-field approximation. Phys Rev $E$ 2012, 85(1):011911.

doi:10.1186/1471-2202-16-S1-P208

Cite this article as: Gollo et al:: Optimal signal detection with neuronal diversity: balancing the gullible and the prudent neurons. $B M C$

Neuroscience 2015 16(Suppl 1):P208.

\section{Submit your next manuscript to BioMed Central and take full advantage of:}

- Convenient online submission

- Thorough peer review

- No space constraints or color figure charges

- Immediate publication on acceptance

- Inclusion in PubMed, CAS, Scopus and Google Scholar

- Research which is freely available for redistribution

Submit your manuscript at www.biomedcentral.com/submit
C Biomed Central 